\title{
AS REPRESENTAÇÕES DAS LUTAS DE INDEPENDÊNCIA NO MÉXICO NA ÓTICA DO MURALISMO: DIEGO RIVERA E JUAN O'GORMAN
}

\author{
Camilo de Mello Vasconcellos \\ Doutor em História Social-FFLCH/USP e \\ Educador do MAE/USP
}

\section{Resumo}

Este artigo trata das representações do movimento de independência mexicana por meio da obra muralista de dois importantes pintores deste país: Diego Rivera e Juan O'Gorman. Estas obras plásticas constituemse em importantes documentos visuais que devem ser analisados à luz de seus contextos de produção aproximando, ainda mais, a relação entre arte e política na América Latina.

\section{Palavras-Chave}

México • Independência Mexicana • Muralismo Mexicano

\section{Abstract}

This article analysis the representation of the Mexican Independence, through the Mexican painters muralists: Diego Rivera and Juan O'Gorman. These paintings are important visual documents that should be viewed in the context of their production, bringing also together the relation between art and politics in Latin America.

\section{Keywords}

Mexico • Mexican Independence • Mexican Muralism 
O tema da independência na América espanhola tem sido consagrado desde o alvorecer das historiografias nacionais do século XIX, como objeto de múltiplas interpretações. O consenso só existe na visão da independência como momento da quebra da dominação política exercida pela metrópole e do nascimento dos Estados Nacionais. De resto, o tema é atravessado por paixões político-ideológicas, tanto da parte daqueles que defendiam uma perspectiva oficialista e ufanista, que no século XIX elegeram os "heróis" que comporiam os panteões nacionais, como da parte de uma historiografia crítica, que em particular nos anos 1960 e 1970, entendeu a independência como um movimento destituído de significativa relevância, pois não teria propiciado a ruptura das grandes estruturas que continuariam a manter a dependência do continente.

Para Maria Ligia Prado ${ }^{1}$ as principais abordagens desta incipiente historiografia do século XIX privilegiavam não só o tema da independência “considerada como o momento de fundação da pátria, mas também seus heróis pensados como artífices dessa hercúlea tarefa" ${ }^{2}$ justificando, portanto, a quebra dos laços com as respectivas metrópoles e a conseqüente legitimação do poder recém constituído.

Neste sentido, em países como a Argentina, o México, o Chile e também o Brasil houve uma proliferação de obras que elegeram as biografias de seus líderes como o tema principal.

Obviamente esta abordagem insere-se na própria concepção de História deste período vista como uma realização de grandes homens. Daí a importância conferida aos líderes.

O que me chamou a atenção nesta obra foi a abordagem da autora no que diz respeito à consagração destes heróis nacionais da independência no campo do simbólico (grifo meu). Para isso, tomou o exemplo das disputas em torno da construção do "herói" Simón Bolívar na Venezuela, que o conduziu da posição de traidor da pátria ao altar de "herói” consolidador da unidade deste país na década de 1840. Ou ainda, no caso mexicano, como foram as controvérsias sobre quem seria o herói da emancipação, uma vez que não só os conservadores difundiam uma visão negativa dos padres Miguel Hidalgo e José

\footnotetext{
${ }^{1}$ PRADO, Maria Ligia Coelho. América Latina no século XIX: tramas, telas e textos. São Paulo: EDUSC/EDUSP, 1999.
}

${ }^{2}$ Idem, p. 29. 
Maria Morelos mas também dos liberais como por exemplo José Maria Luis Mora. Ainda segundo a autora, levou muito tempo para que obtivessem a aceitação como os verdadeiros patronos do processo de libertação nacional mexicano. Somente após a vitória dos liberais com Benito Juarez em 1867 e a conseqüente derrota da Igreja, Hidalgo e Morelos passaram a ser considerados os "heróis" da independência mexicana.

Com certeza as figuras de Morelos e Hidalgo foram ainda mais destacadas no panteão nacional após o processo da Revolução Mexicana de 1910, que consagrou um espaço oficial a todos os seus "heróis" nacionais, que passaram a receber cultos específicos de veneração e admiração por amplas camadas da população desse país, inclusive aqueles que outrora foram considerados "perigosos líderes populares". ${ }^{3}$

Minha abordagem, neste artigo, seguirá o caminho da representação simbólica dos "heróis" da independência mexicana especificamente no século XX por meio das imagens, mais especificamente da obra muralista de dois pintores mexicanos. Para tanto analisarei o mural intitulado La Guerra de la Independencia de México de Diego Rivera (1886-1957) localizado no Palácio Nacional, sede do poder executivo mexicano e também a obra Retablo de la Independencia de Juan O'Gorman (1904-1982) presente no Museu Nacional de História ${ }^{4}$ da Cidade do México.

Meu objetivo será o de apresentar estas obras como documentos visuais que remetem a um determinado contexto político em que foram realizadas, e que estão carregadas de uma simbologia que deve ser analisada cuidadosamente. Além disso, considero também a importância que tais obras assumem, até os dias atuais, na conformação de um imaginário ${ }^{5}$ a respeito não só das lutas de independência no México mas, fundamentalmente, das diferentes visões e projetos políticos dos quais estes pintores são porta-vozes.

\footnotetext{
${ }^{3}$ Op.cit, p.31.

${ }^{4}$ Fundado em 1940 pelo então presidente Lázaro Cárdenas e instalado em um dos mais importantes sítios históricos do México: o Castillo de Chapultepec. Este local foi sede do antigo Colégio Militar no século XIX e a partir de 1864 foi transformado em residência oficial do Poder Executivo Mexicano até a data de sua transformação em instituição museológica. ${ }^{5}$ Para Bronislaw Baczko (1985) "o imaginário social compõe-se de um sistema de representações que trazem junto de si ideologias, aspirações, valores, mitos, utopias e projetos que legitima a ordem estabelecida. Além disso é através dos seus imaginários sociais que uma coletividade designa a sua identidade; elabora uma certa representação de si; estabelece a distribuição dos papéis e das posições sociais; exprime e impõe crenças comuns; constrói uma espécie de código do bom comportamento, designadamente por meio da instalação de modelos formadores tais como o do chefe, o bom súdito, o guerreiro corajoso, etc".
} 
Para tanto, é necessário iniciar esta discussão com questões que considero fundamentais a respeito de um dos mais importantes movimentos artísticos, não apenas do México, mas também da América Latina e da História da Arte Mundial: o muralismo mexicano.

\section{Muralismo Mexicano e o seu Significado ${ }^{6}$}

Não há como desvincular o movimento muralista da história da arte do México, assim como não é possível fazê-lo em relação à própria Revolução Mexicana de 1910. Arte engajada, bíblia política dos pobres, panfleto em escala colossal ${ }^{7}$, inovador ou pouco original, conservador ou moderno, quaisquer que tenham sido as críticas feitas a essa forma de arte, deve-se levar em consideração que arregimentou ao seu redor tanto ferrenhos defensores quanto contumazes opositores ${ }^{8}$.

Localizadas nos principais edifícios públicos da Cidade do México, as obras murais resistem aos críticos e continuam presentes e expostas aos olhares muito ou pouco atentos, desafiando a compreensão sobre as mensagens que pretendem transmitir em toda a sua monumentalidade.

Críticos e historiadores da arte estão de acordo em vincular aspectos da arte muralista não só ao momento da Revolução Mexicana, mas em apontar suas raízes remontando até mesmo ao período pré-hispânico como forma utilizada para expressar valores, crenças e experiências de vida através da arte, como também à forma artística preferida no período colonial na decoração de conventos e igrejas, com intenção evangelizadora. Segundo Julieta Ortiz Gaitán ${ }^{9}$ o século XIX, a independência e os governos liberais que se instauraram, orientaram a arte mexicana para sua secularização, abrangendo espaços civis (edifícios públicos, casas e fazendas) e separando-a dos temas religiosos, além de incorporar

\footnotetext{
${ }^{6}$ Esta reflexão está baseada em minha tese de doutorado intitulada Representações da Revolução Mexicana no Museu Nacional de História da Cidade do México (1940-1982) defendida em setembro de 2003 junto ao Programa de Pós-Graduação em História Social da FFLCH-USP, sob orientação da Profa. Dra. Maria Ligia Coelho Prado.

${ }^{7}$ Essas duas expressões estão referidas na obra de BAYON, Damián. Aventura plástica de hispanoamérica. Pintura, cinetismo, artes de la acción (1940-1972). México: Fondo de Cultura Económica, 1972, p. 24.

${ }^{8}$ Raquel Tibol, historiadora e crítica de arte e ex-secretária de Rivera, é uma das mais entusiastas defensoras da obra muralista. Dentre os seus maiores críticos encontram-se Damián Bayon, Xavier Moyssén e Octavio Paz.

${ }^{9}$ ORTIZ GAITÁN, Julieta. El muralismo mexicano y otros maestros. $1^{\text {a }}$ edición. México: UNAM, Instituto de Investigaciones Estéticas, 1994.
} 
uma rica corrente de arte popular arraigada em tradições e costumes, fonte para a pintura mural do século XX.

A incorporação das tradições populares na arte do século XIX, a laicização dos temas, a busca de um perfil cultural próprio e a revalorização da arte pré-hispânica prepararam o terreno ou deixaram a "mesa posta", conforme Orozco, para que o movimento muralista eclodisse com todo o seu impacto no século XX.

A pintura mural mexicana teve início oficial nos anos 20 do século passado como "filha da Revolução de 1910"10, e foi a principal corrente estética da arte moderna no México, com grande repercussão por todo o continente americano e mesmo na Europa. Não que a Revolução por si só tenha gerado a arte mural, que já estava em estado embrionário, mas, com certeza, foi ela que permitiu sua emergência e esplendor em toda a sua magnitude.

Para Aracy Amaral ${ }^{11}$, o movimento muralista mexicano é a primeira articulação continental dos artistas contemporâneos da América, tendo surgido a partir de sua própria realidade, ou, como disse Germán Rubiano Caballero, “pela primeira vez na história desses países houve uma escola que despertou mais entusiasmo que a academia européia ou qualquer outra manifestação artística do velho continente" 12 . É nesse movimento que Amaral reconhece a primeira forma de expressão plástica que reflete a consciência da realidade mestiça do continente, característica exclusivamente americana, e a exaltação do indígena visto como o primeiro e original habitante dessas terras.

No contexto da história da arte contemporânea, o muralismo mexicano inseriu-se nos debates acerca do papel da arte, situando-se entre as críticas do academicismo do século XIX e o vanguardismo europeu do início do século $\mathrm{XX}$. No entanto, o muralismo respondeu às especificidades do momento político mexicano, de acordo com as condições e objetivos próprios, ao retomar as preocupações do realismo de Coubert e Daumier ${ }^{13}$ voltado para a temática social e para a pintura de trabalhadores e camponeses em cenas cotidianas, sem se afastar dos debates da arte moderna. Ao criar soluções originais para

\footnotetext{
${ }^{10}$ PAZ, Octavio. Pintura Mural. In: México en la Obra de Octavio Paz III- Los Privilegios de la Vista. Arte de México. México: Fondo de Cultura Económica, 1987, p.221.

11 "O muralismo como marco de múltipla articulação.” Primeiro Encontro Ibero-Americano de Críticos de Arte e Artistas Plásticos. Caracas: 1978. (Mimeog.).

${ }^{12}$ Idem, p.4.

${ }^{13}$ CIMET SHOIJET, Esther. Movimiento muralista mexicano - ideologia y producción. $1^{a}$ edición. Universidad Autónoma de México, 1992, p.28.
} 
o uso do espaço pictórico (obras monumentais), o muralismo rompeu com a arte de cavalete e incorporou novos materiais, ferramentas e técnicas ao processo de trabalho.

Mesmo sendo influenciada por movimentos e técnicas européias (especialmente cubismo, fauvismo e expressionismo), a arte na América Latina em geral, e o muralismo mexicano em particular tiveram uma recriação própria a partir da realidade que se vivia, num processo dinâmico de retroalimentação e originalidade ${ }^{14}$. Por conseguinte, não é um movimento unidirecional, em que o modelo vem importado de fora para dentro, e aqui se aceita tal como concebido na Europa; há todo um processo de recriação e construção desde os valores que são vivenciados nesse país e, portanto, nessa especificidade cultural. Esther Cimet analisa:

O fato de haver tido também fontes européias não cancela o valor, a especificidade do movimento muralista. Não é a Europa que explica o movimento. (...) Não são as fontes que explicam um fenômeno artístico, mas o como e o porquê, em que direções se transformam as matérias-primas obtidas dessas fontes. O movimento muralista mexicano bebeu em diversas fontes da história da arte: nos afrescos do Renascimento italiano, nas vanguardas européias e na arte pré-hispânica, colonial e popular do México; mas todas elas juntas não o explicam. O importante é como e em que direção as sintetizou e transformou em outra coisa, e em que consiste esta diferença, em que e como construiu e determinou essa especificidade. ${ }^{15}$

Daí a singularidade desse movimento, que acabou por criar imagens a respeito da história mexicana em seus diversos momentos, ao mesmo tempo em que fundamentou a construção de uma memória plástica referente à Revolução Mexicana.

A Revolução Mexicana, em oposição ao velho regime e às "aristocracias" no poder, engendrou uma nova ordem política que se refletiu também na questão cultural. A cultura tinha que se reconstituir, se renovar, assumir uma nova orientação, mais condizente com os princípios e os objetivos revolucionários,

\footnotetext{
${ }^{14}$ Em termos plásticos a obra de Rivera e Orozco influenciou alguns pintores europeus e norte-americanos, tais como Hastings e Wight Barnes.

${ }^{15}$ CIMET SHOIJET, Esther. Op.cit., p.132.
} 
levando conseqüentemente a um processo de nacionalização da cultura na qual a pintura mural mexicana encontrou seu proeminente lugar.

Para alguns autores, a pintura mural, advinda do processo revolucionário de 1910, é uma arte intencional e plena de significado ideológico, visando a enaltecer e propagandear a obra da Revolução e atingir a maior quantidade possível de espectadores. Daí sua exibição em espaços públicos apresentando aos olhos populares imagens de sua história, permitindo uma leitura pública desses temas a partir de uma visão subjacente a esse movimento artístico e aos interesses específicos do Estado revolucionário.

Por isso, não há como desvincular esse movimento artístico do mecenato do Estado, que contratava os artistas e pagava-lhes salários, garantindo sua existência material unicamente através da atividade artística; oferecia-lhes os muros para o registro de sua arte e de suas idéias; tornava-os reconhecidos por meio do prestígio público nacional e mundial; sugeria-lhes os temas que deviam estar relacionados à história nacional; e, finalmente, deixava-os "livres" para pintar a imagem de um povo em luta pela liberdade, contra a opressão e a tirania.

Essa relação entre arte e Estado, no século XX, lança uma forma inovadora da prática artística, não apenas no que se refere aos temas e signos da arte, mas sobretudo em seus quatro momentos: produção, distribuição, circulação e consumo. Rompendo os canais privados do mercado da arte, amplia seus espaços e suas relações na medida em que ao se localizar em espaços públicos torna-se arte pública, de "consumo" amplo que ultrapassa os limites de um grupo seleto.

A maior parte dos autores pesquisados considera que a origem do movimento muralista ocorreu no ano de $1922^{16}$, podendo ser dividido em duas grandes etapas cronológicas ou gerações: a primeira, que abrange o período entre 1922 até $1942,{ }^{17}$ e a segunda, que vai desde o início da década de 50 até os nossos dias.

A primeira geração está ligada aos nomes de Diego Rivera, David Alfaro Siqueiros e José Clemente Orozco que, reunidos no Sindicato de Operários,

\footnotetext{
${ }^{16}$ Nesse ano Rivera terminou seu primeiro mural denominado A Criação no Anfiteatro Bolívar da Escola Preparatória.

${ }^{17}$ De início, essa primeira geração, antes de abordar temas políticos, históricos e sociais, se ateve a um marco de ideais referentes aos grandes temas da arte ocidental, nos quais se filtravam alguns conceitos próprios da teosofia, do esoterismo, do espiritualismo, e que refletiam o marco ideológico e estético de Vasconcelos. Em seguida surgiram os temas e estilos abertamente políticos relacionados diretamente com temas da história nacional, com os quais se associou mais comumente o movimento muralista mexicano.
} 
Técnicos, Pintores e Escultores, lançaram no ano de 1923 uma "Declaração Social, Política e Estética", no dizer de Raquel Tibol, "de claro sentido populista e subversivo", no qual propunham socializar a arte, produzir apenas obras monumentais para o domínio público, criar uma beleza que sugerisse a luta, repudiar as manifestações individuais e burguesas da pintura de cavalete ${ }^{18}$. O corpo teórico da arte mural nasceu no sindicato, o que marcaria sua vinculação como arte nacional e com uma situação ideológica definida ${ }^{19}$.

Esses ideais propostos pelos muralistas e expressos em suas obras iam ao encontro dos projetos educacionais de José Vasconcelos, Secretário de Educação Pública durante o governo de Álvaro Obregón (1920-1924), cuja proposta era a de vincular a arte mural a um eficaz trabalho semelhante ao dos missionários espanhóis do século XVI: educar pela imagem, procurando atingir, por meio delas, uma população de $85 \%$ de analfabetos.

O desafio era bastante difícil de ser realizado, devido entre outras causas à heterogênea conformação da população mexicana, o que levou Vasconcelos a uma defesa da idéia da mestiçagem na tentativa de tirar o elemento indígena de suas raízes e integrá-lo à sociedade nacional. Daí a idéia de federalizar o ensino e a conseqüente criação da Secretaria de Educação Pública por decreto presidencial de 5 de setembro de 1921.

Em 1922, Vasconcelos contratou os melhores pintores da época para que decorassem os muros dos edifícios da capela de San Pedro e San Pablo, da Escola Nacional Preparatória, e as paredes da Secretaria de Educação Pública, constituindo as primeiras obras murais desse movimento. Com a sua renúncia em julho de $1924,{ }^{20}$ boa parte dos contratos dos muralistas foi suspensa, tendo apenas Rivera continuado seu trabalho.

\footnotetext{
${ }^{18}$ Manifiesto del Sindicato de Obreros, Técnicos, Pintores y Escultores, 1923. Esse manifesto foi assinado, dentre outros pintores, por Siqueiros, Rivera e Orozco. Nesse manifesto, inclusive, esses artistas defenderam explicitamente a candidatura de Plutarco Elias Calles à Presidência da República, contra uma possível candidatura de Adolfo de la Huerta, que havia tentado um golpe contra Obregón nesse mesmo ano.

${ }^{19} \mathrm{O}$ sindicato dos pintores possuía um órgão informativo de nome El Machete, que mais tarde em 1924 se tornaria o órgão informativo do Partido Comunista Mexicano, do qual fizeram parte ativa Siqueiros e Rivera.

${ }^{20}$ Vasconcelos passou a ser alvo de intensas críticas da imprensa, que o acusava de "absurdo messianismo" e também por apoiar "pintores comunistas". Além disso, Vicente Lombardo Toledano, presidente do Comitê de Educação da CROM - Confederação Regional Operária Mexicana -, realizou uma campanha ostensiva contra Vasconcelos por este não apoiar a candidatura de Calles à sucessão de Obregón.
} 
O muralismo mexicano da década de 20 caracterizou-se pelo esforço em criar uma imagem do povo mexicano que surgia das convulsões da Revolução. As origens metafísicas acabaram sendo substituídas pelas realidades derivadas de experiências e preocupações políticas, que constituíram as imagens dominantes nos murais de Rivera, Siqueiros e Orozco.

Rivera, Orozco e Siqueiros acabaram dominando a cena artística no país. Os locais de grande prestígio que eram concedidos a esses pintores marcaram o início da institucionalização do movimento muralista mexicano. Nesse período, os políticos populistas que dominavam o Estado mexicano começaram a perceber nos murais públicos de Rivera um meio para dar uma forma cultural concreta à sua própria participação no desenvolvimento do México pós-revolucionário. Vivia-se o contexto da institucionalização da Revolução da qual Álvaro Obregón (1920-1924) e Plutarco Elias Calles (1924-1928) foram os primeiros a levarem a cabo tal processo. Os murais promovidos pelo Estado refletiam uma interpretação da história mexicana na qual era possível enaltecer as suas realizações. Isto aparece, especialmente, nos murais realizados por Rivera junto às escadarias do Palácio Nacional, intitulados História do México (1929-1935), como veremos mais adiante.

Apesar de sua situação preponderante, o movimento muralista viu-se inserido em uma relação política contraditória com o Estado que o patrocinava: estava sujeito ao Estado, e esta sujeição se dava na forma necessária de uma negociação conflitiva com o Estado patrocinador, tanto nas questões da pintura a ser realizada como na que se referia à sua produção e apreciação.

Cimet Shoijet prossegue:

Há que se levar em conta a relação entre o muralista e seu patrocinador que foi quase sempre conflitiva: nessa relação cada parte trata de defender seus interesses e disso deriva a necessidade de uma negociação entre ambos. Dado que cada mural se realizou em condições conjunturais diversas, dentro de uma correlação variável de forças e a partir de distintas posições também por parte dos muralistas - poderemos considerá-lo como o resultado do confronto dessas forças e não como a expressão quimicamente pura da ideologia do Estado ou de outros patrocinadores, nem tampouco dos interesses que os muralistas representavam. ${ }^{21}$

${ }^{21}$ CIMET SHOIJET, Esther. Op.cit., p.123. 
As visões do mundo moderno criadas por Rivera, Orozco e Siqueiros entre 1930 e 1940 situam-se no contexto de realidades contrastantes. No dizer de Rochfort:

Para Siqueiros constituíam as bases de uma leitura profundamente parcial do mundo moderno. No caso de Orozco, os contrastes com frequiência formaram a premissa de uma interrogação valorativa do conflito entre o ideal e a realidade. $\mathrm{Na}$ obra de Rivera, as dualidades do mundo moderno se trataram numa combinação de posições contraditórias, seja numa visão acrítica e mitificada da modernidade norteamericana ou através da retórica de seu socialismo revolucionário. ${ }^{22}$

$\mathrm{Na}$ década de 40 surgiram os primeiros sinais de desgaste do movimento muralista, que acabaram por acentuar-se na década seguinte. Esse desgaste pôde notar-se na adoção da linha oficialista, no esgotamento das propostas plásticas e no fato de que alguns postulados do muralismo não tinham correspondência com a nova organização econômica e cultural do país, resultante da Guerra Fria.

Na economia do país ocorreu um fortalecimento da participação ativa dos setores industriais e das classes médias; promoveu-se o desenvolvimento de um forte aparato institucional burocrático; introduziram-se novos modelos educativos e culturais e começou-se a sentir sua influência através dos meios de comunicação de massa.

Nesse ambiente, o patrocínio da arte também mudou. O Estado já não era o único promotor cultural ou o mais importante, e tomou força a mercantilização artística com a participação de galerias que promoveram tendências como a abstração ou o geometrismo.

Nesse contexto "desenvolvimentista", que incentivava cada vez mais a industrialização do país, surgiu a produção de murais que introduziram novas propostas, tais como a incorporação do relevo ou o uso de pedras e mosaicos de cores. Passou-se a considerar também o planejamento arquitetônico, e a integração dos murais atingiu seu auge na indústria da construção, durante o qual realizaram-se obras públicas que contaram também com a participação

\footnotetext{
${ }^{22}$ ROCHFORT, Desmond. Pintura Mural Mexicana. Orozco, Rivera, Siqueiros. México: Noriega Editores, 1997, pp. 122-123.
} 
de Orozco, Rivera e outros muralistas. Foi o caso da Cidade Universitária, do Centro Médico, da Secretaria de Comunicações, da fábrica Automex e outros. A história da pintura mural mexicana não terminou em 1974 com a morte de Siqueiros. Existia já desde o final da década de 50 uma nova geração - a segunda - de pintores muralistas, como Carlos Chávez Morado, Juan O’Gorman, Enrico Eppens, Jorge González Camarena e muitos mais. Essa geração se caracterizou pela pintura de murais que buscavam distanciar-se da temática da arte engajada tão empregada pela primeira geração, além de desenvolver estilos mais pessoais e pintar também muros pertencentes à iniciativa privada.

O processo de um mural não termina uma vez realizado. As imagens que a primeira e a segunda geração de pintores muralistas deixou, ainda produzem seus efeitos de grande importância nos dias atuais.

Essas imagens não estão apenas presentes nos espaços públicos do país, mas encontram-se reproduzidas em larga escala também nos livros didáticos distribuídos gratuitamente nas escolas de toda a República, nas propagandas do Partido Revolucionário Institucional (PRI), e nos museus visitados diariamente. Assim, tais imagens vêm sendo consumidas por uma legião de apreciadores cada vez maior, maior ainda que na época em que foram realizadas.

Mais do que nunca essas imagens estão presentes e necessitam serem pesquisadas pelo historiador, trazendo à tona não só as condições de sua produção, mas as suas contradições como produtoras de um poderoso imaginário de efeitos pedagógicos.

Como analisar, então, as obras murais presentes nestas instituições? É necessário deixar claro que as considero muito mais que obras pictóricas elaboradas com a finalidade de serem apreciadas ou experimentadas apenas no aspecto estético. Obviamente não estou desconsiderando que a obra muralista teve enorme importância do ponto de vista das soluções originais quanto ao problema do espaço pictórico (o seu aspecto monumental), à incorporação de novos materiais empregados, às inovações estéticas e, portanto, à linguagem artística como um todo.

Todavia, estas obras devem ser tratadas a partir de suas mensagens e conteúdos veiculados nos distintos momentos da história política mexicana.

É fundamental também ressaltar que essas imagens devem ser vistas como representações, ou melhor, ao serem compreendidas por outras pessoas além daquelas que as produziram, é porque existe entre elas um mínimo de convenção sociocultural. Dessa maneira, elas devem boa parcela de sua significação a seu aspecto de símbolo e de seu poder de comunicação. 


\section{Mural da Independência de Diego Rivera}

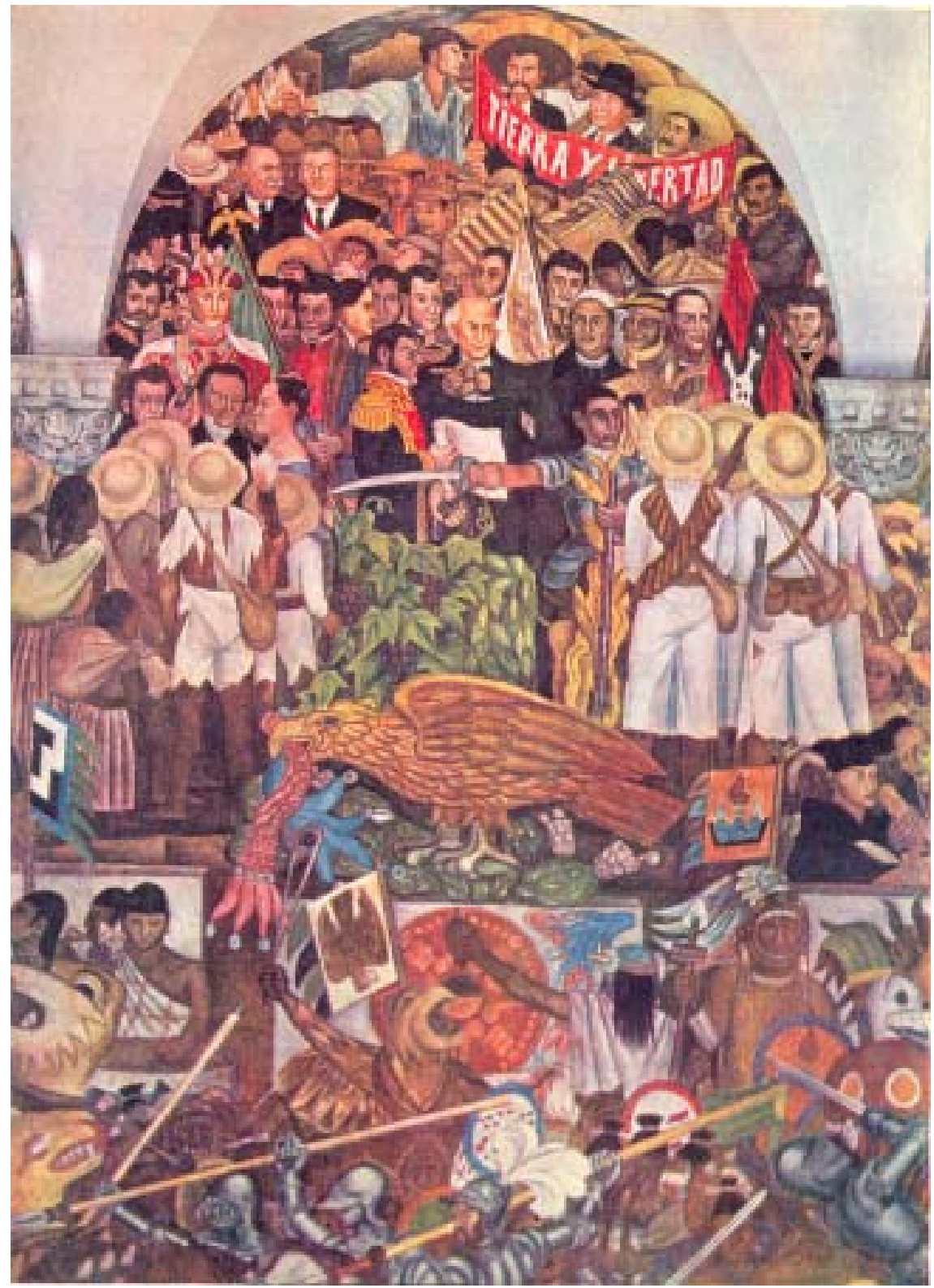

"La Guerra de la Independencia de México (1810)". Diego Rivera (1886-1957), Palácio Nacional, México, D.F, 1929-1935. 
"Meu mural do Palácio Nacional é o único poema plástico que eu conheça que compreende em sua composição a história completa de um povo".

Essa frase de Rivera demonstra, de maneira bastante evidente, que estas obras muralistas do autor, pintadas na sede dos poderes federais, constituíam-se em um de seus maiores orgulhos. Isto porque se configuraram como um dos trabalhos mais ambiciosos de sua carreira e que lhe tomaram maior tempo para realizar, além de ser também o mais polêmico de toda sua carreira de militante político. Quando iniciou estas obras já era um pintor famoso e teve todo o apoio dos governos pós-revolucionários, especialmente de Obregón, Calles e Cárdenas. O processo de criação foi iniciado a partir de 1929, modificou-se parcialmente em 1931, foi retomado em diversos momentos entre 1935 e 1945 e, no início da década de 1950, Rivera considerou o trabalho terminado mesmo que o projeto final tenha permanecido inconcluso.

Nestas representações pictóricas oficiais realizadas no Palácio Nacional, centro das decisões políticas do país e situado no centro histórico da capital federal, o artista propôs uma síntese da história mexicana a partir da época pré-hispânica até o seu momento presente, tendo incluído também uma visão do México futuro.

Vou me deter especialmente na análise da pintura mural dedicada à Guerra de Independência tendo em vista o recorte escolhido para o presente artigo.

Neste mural, Rivera retrata alguns personagens da Guerra de Independência iniciada em 1810 por meio da representação pictórica dos líderes de maior vulto desse fato histórico: Hidalgo e Morelos, de um lado ocupam o centro desta cena, enquanto no canto esquerdo, o Imperador Iturbide, aparece com um peso negativo, aliás o único a ser representado com esta conotação.

Deste grupo central, o padre Hidalgo é o personagem principal que carrega na sua mão direita uma corrente quebrada, simbolizando a liberdade, a ruptura, o fim do domínio colonial enquanto em sua mão esquerda sustenta um estandarte com a imagem da Virgem de Guadalupe.

Ao lado de Hidalgo está o padre José Maria Morelos, o principal general e ideólogo da Guerra. Morelos aponta seu braço para a direita, em direção ao futuro, gesto este acompanhado por um estranho personagem situado mais abaixo que se encontra vestido com uma armadura e uma planta de milho a seus pés como símbolo da terra e que está carregando uma espada em sua mão direita e uma espingarda na esquerda. Da mesma forma que Morelos, este personagem indica, com sua espada, a direção do futuro para um grupo de campo- 
neses armados com rifles e sabres. Seus interlocutores são os camponeses mas também o espectador dos murais.

É importante notar neste detalhe as duas intenções de Rivera como artista engajado politicamente. O primeiro aspecto a ser destacado é a relação e o sentido eminentemente social que o autor empresta às lutas pela independência, expressa na questão da demanda por terras pelos camponeses. Esse aspecto, estabelece uma relação entre passado e presente, pois na guerra pela independência está em questão o "pensamento social mexicano", ou uma "revolução agrária", já anunciando as demandas sociais da Revolução de 1910 e toda a posterior retórica estatal. O segundo aspecto evidenciado por essa temática é a de que os personagens que convocam para a luta transcendem o momento histórico da cena retratada. É antes uma manifestação da própria arte muralista cujo princípio, especialmente o da primeira geração, baseia-se na proposta de que a arte revolucionária contribui para despertar a consciência política das massas e leva a uma ação de sentido social. Mais um grande exemplo da História como representação do presente e para atender aos reclamos de um pintor declarado e assumidamente marxista, tendo sido inclusive membro e um dos fundadores do Partido Comunista Mexicano.

Há que se destacar ainda duas cenas que estão localizadas abaixo e outra acima dos personagens centrais. Na parte inferior vemos a águia, símbolo da nação mexicana; na parte superior a faixa “Tierra y Libertad”, alusão à Revolução Mexicana de 1910.

A representação da águia ocupa uma posição central, um pouco mais abaixo da representação do padre Miguel Hidalgo. Esta imagem está baseada num monumento de pedra pertencente à cultura mexica, encontrado em 1926 na ala sul do Palácio Nacional, outrora o local onde se situava o Palácio de Moctezuma.O ponto principal do monumento, é a águia que sustenta em seu bico uma serpente apoiada sobre um pé de nopales, que simboliza a fundação de Tenochtitlán ${ }^{23}$.

Desta maneira, Rivera se apóia na arqueologia para reforçar o mito que funda a identidade cultural mexicana e serve de vínculo tangível entre o México moderno e seu passado remoto. Deste modo, reforça-se sobre este achado um capital ideológico. É a imagem do centralismo político, como reflexo de um Estado forte, condição que, desde o século passado, se pensava como indispensável para integrar uma nação. O discurso que este símbolo traz refere-se ao mito de origem e a sede do poder político contemporâneo. Este signo

${ }^{23}$ Este inclusive é o símbolo da atual bandeira mexicana. 
torna explícito o fato de que o Estado Nacional pós-revolucionário ocupa precisamente o mesmo sítio que ocupou o centro do poder mexica, o centro do poder vice-reinal e os do século XIX. Visualmente se estabelece então, uma poderosa fonte de legitimidade política.

Já na parte superior, acima dos líderes da Independência, onde se encontra a faixa "Tierra y Libertad", Rivera estabelece uma ruptura cronológica que bem representa a visão do artista acerca da história do México pós-revolucionário. Esse momento é retratado por meio das imagens mais importantes desse período histórico: dois ex-presidentes (Obregón e Calles) e três líderes agrários (Zapata, Carrillo Puerto e José Guadalupe Rodríguez) que sustentam a faixa referida acima. Além disso, surge também representada a efígie do operário internacionalista que assinala o futuro, aludindo à consciência social que este possui do seu próprio destino.

Embora breve, esta imagem é contundente pelo que simboliza e pela mensagem que pretende transmitir. De um lado, há que se considerar uma alusão à tese defendida pelo Partido Comunista do México, em 1929, que assume o deslocamento da solução social do agrarismo-zapatista (ao qual Rivera era simpatizante), para uma revolução soviética liderada por operários e camponeses. Esse deslocamento representa a própria posição do governo pós-revolucionário de apoiar a organização operária em detrimento do avanço da reforma agrária.

De outro lado, esse conjunto de personagens representa a expressão máxima desse momento histórico: a revolução que se fez governo. Daí a presença dos presidentes acima citados, dos líderes políticos que encarnam este fato, de um lado, e dos camponeses e operários, povo produtor e atores do progresso nacional, de outro. Essa composição nos remete evidentemente ao discurso oficial do governo revolucionário instaurado no poder. Há que se lembrar que esta parte do mural provocou uma forte polêmica em torno do pintor e de sua obra, inclusive com a acusação dos comunistas de que Rivera havia se vendido à esquerda contra-revolucionária o que teria levado, segundo o próprio pintor, à sua expulsão dos quadros do Partido Comunista do México.

A genealogia histórica de Rivera perpassa três momentos históricos: a conquista, a independência e a revolução, esta como culminância da disputa pelo poder e sua conquista legitimamente alcançada. Há um fio condutor entre esses fatos, interligados pelos personagens e pelo que eles representam.

Desta maneira, Cuauhtémoc que segura o coração de um soldado sacrificado, na parte inferior do mural, representa a resistência indígena à colonização; Hidalgo, 
com o estandarte erguido da Virgem de Guadalupe representa o início da independência política e Zapata sustentando a faixa ao alto, sustenta a luta pela terra.

Junto a Cuauhtémoc, Hidalgo e Zapata, estão Cortés, Morelos, Allende, Iturbide, Guerrero, Obregón, Calles, operários, camponeses, incluindo a imagem da Virgem de Guadalupe, como se todos representassem uma mesma essência nacional, uma sequiência de fatos históricos que começam no mito da fundação da nação e vai seqüencialmente abarcando toda a história mexicana e que culmina no presente: no Palácio Nacional e na Cidade do México, sede do Estado Nacional Mexicano.

Finalmente, essa composição evidencia o momento histórico em que essa cena é produzida: o momento da consolidação da nação mexicana, ou melhor, da necessidade de sua apreensão, de sua representação e de sua sustentação como símbolo da comunidade dos mexicanos.

\section{Retábulo da Independência de Juan 0'Gorman}

Desde a gestão do historiador Silvio Zavala à frente da direção do Museu Nacional de História (1946-1954) já havia uma firme intenção de convidar os principais pintores muralistas mexicanos para realizarem obras que se relacionassem diretamente com aspectos da história mexicana. Assim, temos neste Museu obras de José Clemente Orozco (La Reforma y la Caída del Império de 1948), de David Alfaro Siqueiros (Del Porfirismo a la Revolución de 1966), de Juan O'Gorman (Sufrágio Efectivo, No Reelección de 1968 e El Feudalismo Porfirista de 1973) e Jorge González Camarena (La Constitución de 1917, de 1967). Esta tradição pode ser buscada já nas palavras do seu diretor quando da inauguração do Museu ao dizer que a tarefa do Museu Nacional de História deveria ser a de "ensinar o público a ver"24.

Diego Rivera também havia sido contratado para pintar um dos principais murais da História Mexicana intitulado Retablo de la Independência a convite do então diretor do Museu Antonio Arriaga Ochoa (1956-1973), chegando a buscar alguns retratos que lhe permitisse desenhar os personagens que apareceriam no mural. Com sua morte, em 1957 Juan O'Gorman acabou sendo designado para o trabalho e empreendeu sua própria pesquisa.

\footnotetext{
${ }^{24}$ José de Jesus Nuñez y Domínguez, Discurso de Inauguración del Museo Nacional de Historia, 27/09/944.
} 


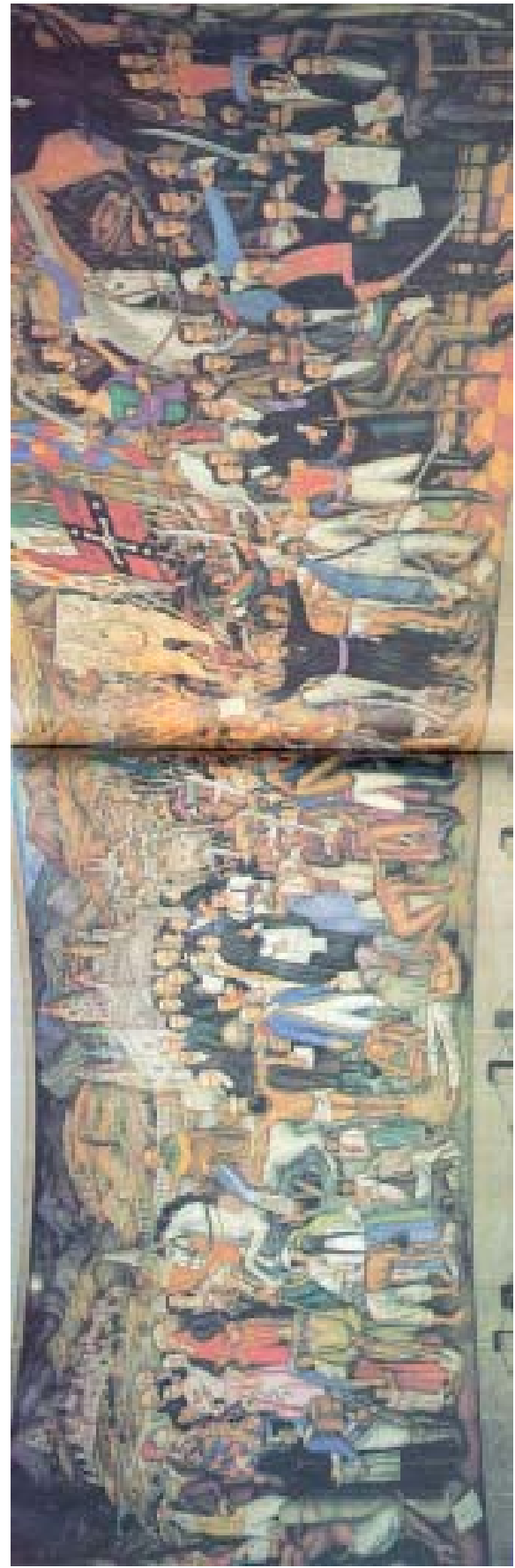

Juan O'Gorman é arquiteto e recebeu influência em seu trabalho do arquiteto franco-suiço Le Corbusier. Realizou diversas obras murais não só pela Cidade do México como também pelo interior do país. É dele a decoração da famosa torre da biblioteca central da Universidade Nacional Autônoma do México (UNAM) realizada nos anos de 1949-1951. Além disso, trabalhou como arquiteto na Secretaria da Educação durante a gestão dos presidentes Pascual Ortíz Rubio (1930-1932) e Abelardo Rodríguez (1932-1934), sob a orientação do então responsável pela pasta da Educação Narciso Bassols e aí se dedicou especialmente aos programas anuais de construção de escolas primárias no Distrito Federal.

Este mural mede 4,40 x 15.69 metros e oferece uma representação teatralizada da guerra de independência, desde seus antecedentes até sua culminância, abarcando o período histórico que abrange os anos de 1784 com as reformas borbônicas até 1814 com o Congresso de Apatzingán que acabou promulgando a primeira Constituição da República Mexicana.

“Retablo de la Independencia” Juan O'Gorman (1904-1982), Museu Nacional de História da Cidade do México, 1961. 
Esta obra, inaugurada em 1961, está dividida em 4 seções que abarcam diferentes etapas da luta pela independência:

A primeira (localizada do lado esquerdo do observador) representa o período prévio ao movimento insurgente e as condições de vida tanto do povo como da aristocracia. Ao lado da bandeira espanhola estão Lucas Alamán, o general Félix Maria Calleja e o bispo Manuel Abad y Queipo, figuras que apoiaram o domínio hispânico; junto a eles vemos um grupo da aristocracia espanhola e abaixo um indígena vítima da exploração, da injustiça e da repressão. Acima dos personagens vê-se uma fazenda, base da economia do país.

A segunda seção representa uma visão geral sobre lugares, pessoas e idéias que antecederam e sustentaram a guerra de independência. Na parte superior, ao lado do edifício neo-clásssico que simboliza a cultura e o avanço científico e a influência do enciclopedismo filosófico e da Revolução Francesa, estão pintadas a cidade de Guanajuato, a igreja de Dolores Hidalgo onde se iniciou o movimento independentista e o edifício onde foram guardadas as munições dos rebeldes (Alhóndiga de Granaditas). Na parte inferior se observam alguns precursores ideológicos da insurgência entre estes estão escritores, cientistas, um grupo de sacerdotes liberais, assim como Francisco Primo de Verdad, prefeito de Guanajuato e Miguel Ramos Arizpe, gráfico da propaganda revolucionária.

A terceira seção (localizada no centro do mural) mostra a luta armada com o padre Miguel Hidalgo como figura principal que aparece duas vezes: primeiro mais jovem em traje de campanha desfraldando o estandarte da Virgem de Guadalupe e logo depois (mais velho) carregando a tocha, símbolo da liberdade, com o decreto de Guadalajara documento importante no qual Hidalgo propunha a abolição da escravidão e a repartição justa da terra. Ao seu lado estão vários personagens de todos os estratos sociais que participaram da luta.

A última parte do mural (do centro para o lado direito do observador) faz alusão ao Congresso de Chilpancingo que ao trasladar-se a Apatzingán promulgou a primeira Constituição Mexicana; encontram-se personagens que se distinguiram nesta fase do movimento, como José Maria Morelos que aparece duas vezes e Vicente Guerrero que consumou a Guerra de Independência. Acima aparece uma paisagem que simboliza a extensão da luta em todo o país: a lua no extremo esquerdo do mural e o sol que nasce no lado direito dão a idéia de que toda a obra abarca um dia simbólico no qual o México passou da obscuridade da dominação espanhola à luz de sua autonomia, ou seja de um novo tempo que se inaugura com a independência do país. 
Nesta sala se exibe também o Estandarte da Virgem de Guadalupe que Hidalgo carregou ao iniciar-se a luta de independência, assim como alguns de seus objetos pessoais e outros de Morelos, atestando a existência material dos heróis da independência mexicana. Tal composição é essencial para conferir dupla legitimidade ao que se expõe, tanto aos objetos, que são "afirmados" nas pinturas históricas, quanto a estas últimas que têm, afinal, a verdade de seus discursos visuais "confirmada" pelos artefatos testemunhais do evento, retratado a posteriori. Reconheço também que reunir objetos históricos e pinturas constituem-se numa forte tendência museográfica existente nos museus históricos latino-americanos. Porém a presença do mural é de tal maneira marcante com todo o seu apelo visual de dimensões monumentais que acaba se impondo e tornando a presença destes objetos materiais secundários, especialmente se levarmos em conta o impacto desta obra mural do ponto de vista do público visitante do Museu.

Este mural constitui-se num dos mais importantes documentos visuais a respeito do tema da independência mexicana presentes na instituição mais visitada da República Mexicana. Pode-se dizer que é uma representação oficial do processo de independência e encontra-se amplamente reproduzido em outros suportes na sociedade mexicana: livros didáticos, campanhas políticas etc.

Sem dúvida este mural contribui na produção de um imaginário a respeito da independência mexicana, onde claramente o maior inimigo era o invasor espanhol apoiado pela Igreja Mexicana, numa leitura liberal da representação deste episódio da história deste país.

Além disso, O’Gorman apresenta também uma leitura maniqueísta do processo de Independência Mexicana trabalhando categorias que representam o bem (o sol, o novo dia que nasce, a independência com Morelos e Hidalgo), o mal (a noite, o obscurantismo do domínio espanhol, os rostos deformados do absolutismo espanhol monárquico), aliado ainda a um imaginário religioso (a representação de um camponês crucificado, o martírio do sofrimento da massa de camponeses sob o jugo espanhol), e outros elementos. ${ }^{25}$

Estabelece-se portanto, as ligações entre imaginário, representação e poder político. E o poder para se impor e sobreviver necessita de legitimidade. O Mural

\footnotetext{
${ }^{25}$ É muito semelhante a abordagem deste mesmo pintor de outra obra muralista também presente no Museu Nacional de História denominada Sufrágio Efetivo, Não Reeleição, pintada em 1968 e analisada em minha tese de doutorado.
} 
de Juan O'Gorman presente no Museu Nacional de História acaba integrando o universo simbólico que legitimou o poder político mexicano até os dias atuais.

Os murais aqui analisados mostram a vinculação existente entre o campo da arte e o da política, entre o objeto artístico e as idéias fundadas em uma necessidade política. Mas neste contexto, seria um erro pensar que aqueles artistas ou intelectuais ligados à promoção oficial tivessem sido meros transmissores da ideologia estatal. O alicerce da cultura é sumamente complexo e é muito difícil estabelecer a origem e a direção dos fios que o conformam. Entre outras razões porque, como em todas as épocas, existem preocupações que pertencem à sociedade e são alvo das mediações entre o artista, a sociedade e quem os contrata.

Nos anos em que Rivera pintou sua história do México, o enigma a ser resolvido era o da nação mexicana em um momento em que a Revolução, agora no poder, passava por sua institucionalização. Com O'Gorman, o contexto político era outro e o poder político oficial buscava sua legitimação ao apropriar-se da leitura da Independência como comparativo dos novos tempos vividos pela Revolução de 1910, numa espécie de legado ou herança a ser preservada até os dias atuais.

Estas imagens, que conjugaram força estética e didática, revelaramse até os dias atuais, muito competentes na tarefa de despertar a sensibilidade dos corações e das mentes dos visitantes e observadores que cotidianamente comparecem como numa verdadeira peregrinação cívica, a revisitar os seus "heróis" mitificados.

\section{Referências Bibliográficas}

AGUILAR CAMÍN, Héctor. Nociones presidenciales de "cultura nacional". De Álvaro Obregón a Gustavo Díaz Ordaz. In: En torno a la cultura nacional. México: Instituto Nacional Indigenista y Secretaria de Educación Pública, 1976.

\& MEYER, Lorenzo. A la sombra de la Revolución Mexicana.

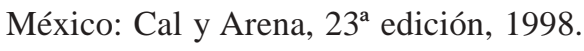

AMARAL, Aracy A. O muralismo como marco de múltipla articulação. Primer Encuentro Iberoamericano de Críticos de Arte y Artistas Plásticos. Caracas, 18 al 27 de junio de 1978.

BACZKO, Bronislaw. Imaginação Social. In: Enciclopédia Einaudi. V.5, Lisboa: Imprensa Nacional/Casa da Moeda, 1985. 
BAYÓN, Damián. Aventura plástica de hispanoamérica. Pintura, cinetismo, artes de la acción (1940-1972). México: Fondo de Cultura Económica, 1972.

BENJAMÍN, Thomas. La Revolución: Mexico's great revolution as memory, myth and history. University of Texas Press, USA: 2000.

CIMET SHOIJET, Esther. Movimiento muralista mexicano. Ideología y producción. México: Universidad Autónoma Metropolitana - Unidad Xochimilco,1992.

EDER, R. Muralismo Mexicano: modernidad e identidad cultural. In: BELLUZZO, A. M. M. (org.). Modernidade: vanguardas artísticas na América Latina. São Paulo: EDUNESP, Memorial, 1990.

MATUTE, Álvaro. La Revolución Recordada, Inventada, Rescatada. Memoria del Congreso Internacional sobre la Revolución Mexicana. San Luis Potosí, Instituto Nacional de Estudios Históricos de la Revolución Mexicana, vol.2. México: Octubre, 1991.

NÚÑEZ Y DOMÍNGUEZ, José de Jesús. Discurso de inauguración del Museo Nacional de Historia. In: El Excelsior, 27.9.1944.

O'MALLEY, Ilen V. The Myth of the Revolution. Hero cults and the institutionalization of the Mexican State, 1920-1940. Greenwood Press. New York, Westport, Connecticut, London: 1993.

ORTIZ GAITÁN, Julieta. Imágenes de Arte Mexicano. El muralismo mexicano otros maestros. México: UNAM, Instituto de Investigaciones Estéticas, 1994.

PAZ, Octavio. Los privilegios de la vista: Arte de México. México: Fondo de Cultura Económica, 1984.

PRADO, Maria Ligia Coelho. América Latina no Século XIX: Tramas, Telas e Textos. São Paulo: Editora da Universidade de São Paulo, Bauru: Editora da Universidade do Sagrado Coração, 1999.

ROCHFORT, Desmond. Pintura Mural Mexicana. Orozco, Rivera y Siqueiros. México: Noriega Editores, 1997.

RODRÍGUEZ MORTELLARO, Itzel. La Nación en los murales del Palacio Nacional (1929-1935). In: Los murales del Palacio Nacional. México: Américo Arte Editores, 1997.

RODRÍGUEZ PRAMPOLINI, Ida. Juan O' Gorman Arquitecto y Pintor. México: UNAM, 1982.

y otros. La palabra de Juan O' Gorman (organiz.). México: UNAM, Instituto de Investigaciones Estéticas, 1983. 
TIBOL, Raquel. Obras Monumentales en el Museo Nacional de Historia. In:

Tesoros del Museo Nacional de Historia en el Castillo de Chapultepec. México: CNCA, INAH, 1994.

Documentación sobre el arte mexicano. México, Fondo de Cultura Económica, 1974.

Palacio Nacional en el tormento muralista mexicano. In: Los murales del Palacio Nacional. México: Américo Arte Editores, 1997.

VASCONCELLOS, Camilo de Mello. Representações da Revolução Mexicana no Museu Nacional de História da Cidade do México (1940-1982). FFLCHUSP, 2003. Tese de Doutorado. 